\title{
Computer Generated Works and Copyright: Selfies, Traps, Robots, AI and Machine Learning
}

Dr Paul Lambert

\author{
European Intellectual Property Review
}

\begin{abstract}
Summary
Many copyright laws were expanded to embrace computer generated works. What was understood by the expansion and what it protected are also referred to. Since the first generation of computer generated works protected by copyright, the types of computer generated works have multiplied further. This article examines some of the scenarios involving new types of computer generated works and recent claims for copyright protection. This includes contextual consideration and comparison of monkey selfies, camera traps, robots, artificial intelligence (AI) and machine learning. While often commercially important, questions arise as to whether these new manifestations of copyright works are actually protected under copyright at all.
\end{abstract}

\section{Introduction}

Photographs are valuable commercially and are recognised as deserving copyright protection. The value in copyright works is frequently enforced by way of infringement litigation. ${ }^{1}$ However, new forms of taking photographs are evolving with advances in technology. Some are automated and occur in the absence of a human photographer. Increasingly, important questions arise as to whether these are copyright protected or not.

\section{Copyright background}

The noble artistic/literary copyright embrace has expanded over time. Indeed the commercial copyright embrace has also expanded. One aspect of the expansion relates to software programs and software creations. ${ }^{2}$ This encompasses direct human creations of computer programs and the like.

However, this would not protect further down-the-line indirect computer-created or computergenerated works which are technically created by the computer as opposed to the person. In order to protect such down-the-line computer created works the copyright regime would have to expand yet further. Given this problem, there are examples of further express copyright extensions to cover this very problem of computer generated works being created but being devoid of protection. A number of copyright laws have been expansive in order to embrace and recognise the existence of and to protect computer generated works.

The expansion to protect computer-generated works has existed for some years. It is beneficial, if not increasingly necessary, to now consider that the world of such computer generated works has also expanded over time, albeit over a more compressed temporal timespan. The issue now is that those expansions occurred quite some time ago.

The problem and the solution recognised in the copyright expansion embracing computer generated works are highlighted below. What was understood by the expansion and what it protected are also referred to. The forms of computer generated works have expanded since the time of the problem of copyright and the need to protect computer generated works. However, since the first generation of

$1 \quad$ As an example, see Y.H. Lee "Photographs and the standard of originality in Europe: Eva-Maria Painer v Standard Verlags GmbH, Axel Springer AG, Suddeutsche Zeitunung GmbH, Spiegel-Verlag Rudolf Augstein GmbH \& Co KG, Verlag M. DuMont Schauberg Expedition der Kolnischen Zeitung GmbH \& Co KG (C-145/10) (Case Comment)" E.I.P.R. 2012, 34(4), 290; Richardson Computers Ltd v Flanders (No.2) [1993] F.S.R. 497.

2 P. Muffo, "Protection for Software Creations" (2015) 35(9) The Licensing Journal 23. Also note "Copyright Protection in 'Machine Instruction Set' for Microcontrollers: Microchip v Micon", E.I.P.R. 2011, 33(7), 461. 
computer generated works protected by copyright, the types of computer generated works have multiplied further. The discussion below examines some of the modern scenarios involving new types of computer generated works and recent claims for copyright protection. This includes contextual consideration and comparison of examples such as monkey selfies, camera traps, robots, artificial intelligence (AI) and machine learning. Increasingly there are commercial imperatives as to whether value and creativity are protected.

\section{Copyright and computer produces "works"}

Clark and Smyth refer to the problem which originally arose for computer generated works. They state that "[i]f something is produced by a natural force by non-human intervention then that product cannot be a "work' for a work requires the presence of an author." The original problem being that the work produced by the computer is divorced and separate from the original creator of the computer or computer program, and it the computer creating a new work - but without an author. This problem is further expressed by Clark and Smyth,

"A work that is produced by a human being who produces that work by using a typewriter or word processor is clearly not deprived of protection because of the mechanical means used to fix the work, but problems arise where the work is created after a computer produces that work following upon a program being written and used in order to generate the work."

The authors note the case of Express Newspapers Plc v Liverpool Daily Post and Echo ${ }^{5}$. In that case the work product of the computer program was protected, the computer being viewed as a tool "by which the literary work could be produced via the operation of the computer program." ${ }^{\prime 6}$ The authors Clark and Smyth continue however, and note that,

"where the work is produced by a machine - a satellite photograph or even some computer code generated by that machine with minimal human input - some difficulties will arise. A distinction between computer aided [works] (eg computer aided designs) and computer generated works is found in the literature and the distinction was approved in the ... South African case of Payer Components South Africa Ltd v Bovic Gaskins. ${ }^{7}$ The importance of such a distinction is that works within the first category will be protected as original works while those in the second category will not, unless individual jurisdictions amend copyright law to afford protection to those works and identify who the rightholder is to be and for how long the right is to last." $"$

According to this analysis, computer aided works are copyright protected under the normal preexisting copyright arrangement. However, computer generated works are not encompassed and not protected. Thus, for computer generated works to have protection, the copyright regime would need to be expressly expanded to encompass such works. Indeed, given the problem of new computer generated works being created which had no protection, it was deemed appropriate to amend copyright laws to expressly include protection for computer generated works - as they were understood at the time. If there was no extension, no protection exists for computer generated works.

\section{Express expansion to protect computer generated works}

A number of express extensions to current copyright laws were enacted to deal with the (then) problem. Section 9 of the UK Copyright, Designs and Patents Act 1988, for example, provides that "author" in relation to a work, "means the person who creates it". "That person shall be taken to be ...

Clark and Smyth, Intellectual Property Law in Ireland (Dublin: Butterworths, 1997), p. 252. Emphasis added.

Ibid.

[1985] 1 WLR 1089; [1985] 3 All E.R. 680; [1986] E.C.C. 204; [1985] F.S.R. 306; (1985) 129 S.J. 606.

Clark and Smyth, above, p. 252.

[1995] 33 IPR 407.

Clark and Smyth, above, pp. 252 - 253. Emphasis added. 
(3) In the case of a literary, dramatic, musical or artistic work which is computer-generated, the author shall be taken to be the person by whom the arrangements necessary for the creation of the work are undertaken". Thus, computer generated works are protected by copyright, and the owner or author is the person whom makes the arrangements necessary for the creation of the work, ie the arrangements for computer generated work.

Section 12(3) of the UK 1988 Act also refers to the term of protection for the computer generated work. Protection shall last for 70 years from the end of the year of creation. Section 9(3) as indicated above refers to whom the rightholder will be as regards the computer generated work. Clark and Smyth state that "[i]n deeming this person to be the author, the Act makes clear that authorship is entrepreneurial rather than being creative in nature: a more neutral meaning of author would be the technical staff who collectively or alone enabled the computer to generate the work." interesting to consider issues such as employees whom enable the computer to generate the work or whom make the arrangements necessary for the creation of the work; and whether presumption of employee copyright belonging to the employer arise (where such presumptions exist) in relation to such computer generated works.

Section 2(1) of the Irish Copyright and related Rights Act 2000 also refers to computer-generated works. It defines a computer-generated work as meaning "that the work is generated by computer in circumstances where the author of the work is not an individual". This recognises that the computer generated work is down-the-line from the person creating the computer or computer program. The Act also defines a "computer program". A computer program "means a program which is original in that it is the author's own intellectual creation and includes any design materials used for the preparation of the program". The Act states that "'author' means the person who creates a work and includes "(f) in the case of a work which is computer-generated, the person by whom the arrangements necessary for the creation of the work are undertaken". Similar to the UK Act, copyright protection has been extended to computer generated works. The owner is the author whom makes the arrangements for the creation of the work (subject to any employee presumptions which may apply). The indication that the per se rule is that the author is the person whom creates the work but that an additional and separate rule needs to apply for computer generated works confirms that computer generated works are down-the-line. The reference to the creation of a work as distinct from making arrangements which will lead to the creation of a work (which will occur separately or down-the-line) is further recognition of the problem. Without amendment to the previous copyright regime position, the creation of a work down-the-line which is without an author (or a person as author) was devoid of protection.

That there was a problem of an absence of protection for computer generated works is recognised in the expanded embrace of copyright to these works. However, what was the then understanding of computer generated works and what the copyright expansion would mean? The original understanding is in part recognised by Clark when he refers to the expansion of "recognition that a computer-generated work may attract copyright will be of considerable importance to the artistic community." ${ }^{10}$ The philosophy had to some extent an artistic (and literary) aspect of appreciation in mind. As J. Grimmelmann also notes, "[c]opyright's ideal of [a] romantic readership involves humans writing for other humans."11 Even with copyright for (certain) computer generated works in mind, there is still an artistic and artistic community - if commercially artistic - notion at play.

However, new technological events and new modern examples of computer generated works are much more advanced than when the original expansion occurred (for instance in 1988). The new examples are increasingly further-down-the-line from human direction or arrangement. Is there a point on the line beyond which extended copyright protection does not protect? Are new computer works beyond that point devoid of protection?

$9 \quad$ Clark and Smyth, above, p. 253.

10 R. Clark, Irish Copyright and Design Law (Dublin: Butterworths, 2003), p. B/85. Emphasis added.

11 J. Grimmelmann "Copyright for Literate Robots" (2016) 101(2) Iowa Law Review p. 657. 


\section{The happy monkey and the selfie}

One of the more interesting popular copyright disputes involved whether a photograph taken on a tourist's camera was copyright, and if so who owned it. Unfortunately for the camera owner, the fact that the now famous "selfie" photograph was taken unbenownst to them by a monkey meant the issue resolved on whether a photograph taken by an animal, or in this case the monkey, can give rise to copyright protection. The parties involved were the tourist, Slater, and one of the publishers of the photograph once it became famous, namely, Wikimedia (part of Wikipedia). ${ }^{12}$

The case was brought by British photographer David Slater based on copying and alleged infringement of photographs taken a the crested black macaque monkey in Indonesia. He claimed to own the copyright in the photographs because he owned the camera on which the photographs were taken. Wikimedia in defence claimed that the photographs do not fall under copyright protection, are public domain, all because they were taken by a monkey, and not a human person. ${ }^{13}$ There also appears to be some reports of Wikimedia suggesting that the monkey has copyright and not the claimant. Ultimately, the photographer was unsuccessful. He was unsuccessful at least in so far as the US Copyright Office decided not to register the copyright, which might be distinguished from an actual formal copyright infringement case in a court. The Copyright Office reportedly said that "[t]he Office will not register works produced by nature, animals or plants." The Copyright Office Copyright Compendium $\S 202.02$ (b) states that "[t]he term 'authorship' implies that, for a work to be copyrightable, it must owe its origin to a human being. Materials produced solely by nature, by plants, or by animals are not copyrightable." Sam Ricketson refers to the need for human authorship in relation to obtaining copyright protection. ${ }^{14}$

\section{Training}

Many animals, perhaps none more so than certain monkeys can be trained to varying degrees. This can include training and instructing a monkey to undertake various tasks and sometimes a level of communicating - even using sign language.

One might consider a situation where a monkey is taught to use a camera and instructed or directed to take certain photographs. The equipment, the teaching and the individual direction to take an instant photograph or series of photographs are all within the control of a person. In this instance, one might suggest that the claim for copyright is altogether different, if not stronger, than the arguably accidental monkey selfie under the so called test in the Slater $v$ Wikimedia example. Yet, there is no human involvement and no mechanical apparatus directed or triggered by a human, thus raising potential for conflict with the US rule, and possibly also UK and Irish rules for example.

Another scenario may involve a group of monkeys in a controlled environment where a camera or cameras are placed in position where it is inevitable that some photographs will be taken, and that may be the intention of the project. In this instance, there is a leaning toward a deliberate, coordinated result versus an accidental selfie. One would image that a professional photographer or professional art project may expect that "their" photographs will be copyright protected and commercial. Notwithstanding that there are many stronger factors of expectation to the professional photographer,

12 S.N. Weller, "Copyright Ownership is Not Monkey Business: Wikimedia and Slater Fight Over Selfie Photographs” (2014) 20(5) IP Litigator p. 33. C. Clinton, "Monkey Says 'Cheese,' copyright Battle Ensues" Wisconsin Law Journal (08/2014). J.L. Muse, "Monkeys, and Elephants and Koalas, Oh My! Is Originality Still the Touchstone of Authorship in United States Copyright Law? (2015) 97(4) Journal of the Patent and Trademark Office Society p. 736.

13 S.N. Weller, "Copyright Litigation" (2014) 20(5) The IP Litigator: Devoted to Intellectual Property Litigation and Enforcement p. 33.

14 S. Ricketson "The need for human authorship - Australian developments: Telstra Corp Ltd v Phone Directories Co Pty Ltd (Case Comment)" E.I.P.R. 2012, 34(1), 54. 
it is not clear that they are in a position any stronger than the accidental selfie in Slater $v$ Wikimedia if the test remains solely that the issue rests or falls on the monkey or a person doing the physical clicking for the photograph.

\section{Trapped photographs}

Many television viewers will be familiar with wildlife programmes which have photographs and footage of hard to find animals in the wild. In many instances these are possible because of camera trap photography. Particular types of resilient camera equipment with sensor technology are placed in remote locations where it may be hoped that wild animals, and even particular species, may pass by. If one does pass by, the equipment will do the work and take a photograph (and or video). The monkey, rare big cat, etc., is not taking the photograph. Nor is there a Slater $v$ Wikimedia selfie situation present. Much of this footage is eventually commercialised, and also promotes a valuable conservation message, and requires copyright protection in order to do so. It would appear not to fall foul of the monkey selfie rule. However, there is no person or photographer present. So while these trapped photographs may not yet have been challenged or had to be enforced in terms of copyright protection, someone having to do so in future may have to consider the particular configuration of the equipment, computing, etc., and whether these photograph can be deemed to be so proximate to a person as to be theirs, or whether the decision, trigger or action of taking the photograph is so far down-the-line of events that the concept of a computer generated work or computer action photograph needs to be considered in detail. Is the particular equipment a computer as envisaged? Is the photograph computer generated as envisaged and as defined?

A further computer or algorithmic element might be introduced to the problem also. One of the issues with trapped photographs is that many photographs may be taken, but only a small percentage have the animal sufficiently central or centred in the image to be of public television quality. Consider the development of software or a device which makes decisions or assessment on the spot, and will only take photographs of a sufficient quality or sufficiently centered? One could also conceptualise software which might assess the size, shape and distance of an animal in deciding to take a photograph, whether to zoom-in, etc. Furthermore, if one is considering a particular type of rare big cat, we may not be far away from software and devices which ignore other big cats and other animals entirely, and only focusing on the particular quest. The point is that these examples take us further again along the line of events that the balance towards computer generated works or images, albeit not a direct person undertaking the instant tasks.

\section{The quantified self}

The whole field of wearable devices, wearable sensors and the quantified self offers one of the more important challenging legal and policy areas in contemporary society. To an extend these and other developments are encapsulated in the umbrella term internet of things (IoT). Various individuals are seeking to record as much of their lives and daily activities as possible. This quantifying of one's daily activities comes within the quantified self endeavour (in this instance capturing photographic or video images). There are a number of notable examples. ${ }^{15}$

In some of these instances the camera (or related recording device) takes an image every number of minutes or seconds (a time-setting basis). Over time this builds up into a significant library or database of images. The camera can also operate on a trigger or event or other basis. While the time setting images are closer to the typical understanding of a photographer copyright (even time lapse or

15 One of the earliest examples and indeed proponent of recording the quantified self is Stephen Wolfram. He refers to this at his blog at http://blog.stephenwolfram.com/2012/03/the-personal-analytics-of-mylife/. See also, for example, R. Picard and G. Wolf "Sensor Informatics and Quantified Self” (2015) 19(5) IEEE Journal of Biomedical and Health Informatics 1531; M.B. Hoy "Personal Activity Trackers and the Quantified Self” (2016) 35(1) Medical Reference Services Quarterly 94; R. Eynon “The Quantified Self for Learning: Critical Questions for Education” (2015) 40(4) Learning, Media and Technology 407; P. Moore and A. Robinson "The Quantified Self: What Counts in the Neoliberal Workplace" (09/2015) New Media \& Society. 
delay setting), more interesting queries may arise where the photographer is not directly choosing each image which occurs in a more random opportunity and random basis. The extent to which a computer, algorithm or computer robot may be involved in "deciding" to take each of these later individual photographs will raise interesting argument if and when they come to be tested.

Consider also the situation where the person wearing a type of body camera, may or may not own the device, but also is not the person whom has developed the computer, algorithm or computer robot. It may be difficult for the wearer of the body camera to suggest that they have taken the photograph, or created the other circumstances surrounding the taking of individual photographs (other than, perhaps, location). To argue that the equipment owner has a claim to be the copyright ownership per se may also be very difficult - particularly is the equipment is standardised and widely publically available. We are then left with the difficult nuances of describing and considering when the developer's role ends and when the computer generated work may arise. When does complex technology leave a select specialised user base to a mass market user base, and how does this interact with further-down-theline issues? As quantified self endeavours continue it seems that difficult consideration will be needed as to when and to what extent the images (or other products) of the captures are produced by a computer, robot, algorithm, developer or mass user base.

\section{Drones}

Much of the recent commentary in relation to drones refers to drones which are directly controlled by an owner or operator, from military strike drones, ${ }^{16}$ law enforcement, ${ }^{17}$ personal "domestic" drones ${ }^{18}$ to professional drones such as emergency services, auctioneer sales picture drones, etc., and humanitarian drones. ${ }^{19}$ All of these are operated directly by an individual person. It is partly due to this that the ownership of domestic personal drones and profession drones are increasingly subject to regulation and even obligatory licensing. ${ }^{20}$ The US Federal Aviation Authority, the Civil Aviation Authority in the UK and Irish Aviation Authority, for example, issue drone licenses and administer registration.

However, there are other types of drones. These other drones raise the question of whether there is any human involvement in the immediate decisions, actions and control at the operative time downthe-line ${ }^{21}$. There are many examples of autonomous drones. These include autonomous flying drones, autonomous aquatic surface drones and autonomous sub aquatic drones. The question of whether setting a mission so to speak, means that that can be equated with the decision of an autonomous

16 For example, S Gardiner "The Domestic Criminal Legality of the RAF Drone Strike in Syria in August 2015" (2016) 1 Criminal Law Review p. 35; G-J. A. Knoops "Legal, Political and Ethical Dimensions of Drone Warfare Under International Law: A Preliminary Survey (2012) 12(4) International Criminal Law Review p. 697; K. Benson “"Kill 'Em and Sort It Out Later': Signature Drone Strikes and International Humanitarian Law” (2014) 27(1) Pacific McGeorge Global Business \& Development Law Journal p. 17; G-J. A. Koops "Drones at Trial. State and Individual (Criminal) Liabilities for Drone Attacks" (2014) 14(1) International Criminal Law Review p. 42.

17 For example, M.L. Smith "Regulating Law Enforcement's Use of Drones: The Need for State Legislation" (2015) 52(2) Harvard Journal on Legislation p. 423. E Brumfield "Armed Drones for Law Enforcement: Why It Might Be Time to Re-examine the Current Use of Force Standard" (2015) 46(3) McGeorge Law Review p. 543. Also note on regulation generally R Carver, "State Drone Laws: A Legitimate Answer to State Concerns or a Violation of Federal sovereignty?" (2015) 31(2) Georgia State University Law Review p. 377.

H.B. Farber "Eyes in the Sky: Constitutional and Regulatory Approaches to Domestic Drone Deployment" (2014) 64(1) Syracuse Law Review p. 1.

19 K.B. Sandvik and K. Lohne "The Rise of the Humanitarian Drone: Giving Content to an Emerging Concept" (2014) 43(1) Millennium - Journal of International Studies p. 145.

20 M. Barbee, "Uncharted Territory: The FAA and the Regulation of Privacy Via Rulemaking for Domestic Drones" (2014) 66(2) Administrative Law Review p. 463; T.A. Rule "Airspace In An Age of Drones" (2015) 95(1) Boston University Law Review p. 155.

21 R. Berkowitz "Drones and the Question of "The Human"” (2014) 28(2) Ethics \& International Affairs p. 159. 
drone to take an instant photograph or image becomes more difficult as the technology advances. In instances where photographic action becomes ever more extended down-the-line from the contemporary activity of an initial person, those seeking to own and or control use of later images may have to consider concepts such as copyright in computer created works. Protection for new commercialisations which are potentially further-down-the-line from a human are going to become increasingly complicated.

\section{Machine learning and AI}

One of the other new considerations in relation to copyright and computer generated works includes the development of machine learning and artificial intelligence (AI). H. Surden refers to machine learning, AI and law, and describes the technology as follows, "Artificial intelligence (AI) ... [and] machine learning involves computer algorithms that have the ability to 'learn' or improve in performance over time on some task." 22

Machine learning and AI are sought to be applied to Cloud computing, the internet, social networking facial recognition, ${ }^{23}$ medicine, ${ }^{24}$ travel and accommodation, ${ }^{25}$ robotics, ${ }^{26}$ AI drones, and many other activities. There are a number of areas, activities and decisions where it is proposed that humans can be taken out of the process, including legal decision making and legal advice. ${ }^{27}$ While there are many issues raised ${ }^{28}$, copyright is indeed one of these. In many of these new activities, photographs and images are taken by the automated robots and AI machines. This occurs without a human present or directing. The issue then arisies as to whether these new photographic works are commercially protected as copyright. This is not an inconsiderate question given the vast financial resources being devoted to robot, drone, machine learning and AI both in research terms and commercialisation terms. While this may be less relevant in certain instances, the very viability of rolling out the new technology and devices may be contingent upon copyright and a route to return on investment.

However, as J. Grimmelmann notes, frequently "[c]opyright ignores robots." ${ }^{29}$ This applies equally to machine learning and AI. Indeed the concepts of robots, machine learning and AI overlap. Yet, important commercial decisions may come to depend on whether these new autonomous works and activities can be protected. Given that they are even further down-the-line from the equipment manufacturer and developer, and considering that these new activities were not envisaged when certain modern copyright statutes were extended, companies may have to consider whether they can be pidgeon-holed into the previous concept of defined computer generated works. We cannot be fully assured that they are all covered by the various legal copyright extensions.

22 H. Surden "Machine Learning and Law" (2014) 89(1) Washington Law Review p. 87. The article refers to and analyses the potential applicability of AI to legal practice and legal tasks. Overall, "To the contrary, many of the tasks performed by attorneys do appear to require the type of higher order intellectual skills that are beyond the capability of current techniques". "It is not suggested that all, or even most, of the tasks routinely performed by attorneys are automatable given the current state of AI technology". However, "there are subsets of legal tasks that are likely automatable" under certain circumstances.

A. Vinay, V.S. Shekhar, J. Rituparna, T. Aggrawal, K.N.B. Murthy and S. Natarajan, "Cloud Based Big Data Analytics Framework for Face Recognition in Social Networks Using Machine Learning" (2015) 50 Procedia Computer Science 623. R.C. Deo "Machine Learning in Medicine" (2015) 132(20) Circulation p. 1920.

Y Yang, J. Tang, H. Luo and R. Law "Hotel Location Evaluation: A Combination of Machine Learning Tools and Web GIS" (2015) 47 International Journal of Hospitality Management p. 14. "Researchers at University of London Imperial College Release New Data on Robotics (AIonAI: A Humanitarian Law of Artificial Intelligence and Robotics)" (02/2015) Robotics \& Machine Learning p.1526.

27 H. Surden, "Machine Learning and Law" (2014) 89(1) Washington Law Review 87. Also note $R$. Susskind, The Future of Law (Oxford: OUP, 1996); R. Susskind, Transforming the Law (Oxford: OUP, 2000); R. Susskind and D. Susskind, The Future of the Professions (Oxford: OUP, 2015). L. Bottou "From Machine Learning to Machine Reasoning: An Essay" (2014) 94(2) Machine Learning p. 133.

J. Grimmelmann “Copyright for Literate Robots” (2016) 101(2) Iowa Law Review p. 657. 
Sometimes these issues also involve discussion of "electronic agents". ${ }^{30}$ Machine learning and robotic actions can also occur at distance, such as teleoperated robotic systems to enabling action at a distance or "tele-agency" 31 Tele-agency can extend "across the traditional physical boundaries of legal jurisdiction". "Ironically perhaps, this could mean that the distance down-the-line is a relevant factor to consider.

The necessary consideration of whether these new activities do fit into the definition of computer generated works is not an altogether simple task.

The statutes referred to above, which refer to computer generated work copyright protection, provide the following,

\section{UK Copyright, Designs and Patents Act 1988}

"author" "means the person who creates it".

"In the case of a literary, dramatic, musical or artistic work which is computer-generated, the author shall be taken to be the person by whom the arrangements necessary for the creation of the work are undertaken".

There is no easy assurance that this would automatically include new technology and works which may be created by new means not previously envisaged. There is the potential for the above provision to be interpreted as covering situations where the deemed author, the arrangements necessary and the creation of the work are all proximate, thus excluding situations where the end work is created very far down-the-line autonomously from the person, indeed with the person not being present at all. There is likely to be detailed discussion, if not debate, in relation to what "arrangements" and "arrangements necessary" actually means. Also, argument might suggest, for example, that "arrangements" are something different from actual equipment or technology. Even if "arrangements" includes creating and developing a particular robot, machine learning automation, AI or internet of things (IoT) device, application or operation, there is still scope to separate or rather distinguish the arrangement qua device from the operation of the device, for example, in taking photographs or certain individual photographs. That is, developing or building the equipment device does not relate to individual actions and operation with the device nor the product of that device per se or when the device is undertaking autonomous creative actions. To what extent are the previously understood arrangements different to, and similar to, the arrangements (and other actions) in the new robot, machine learning, AI or internet of things (IoT) world?

Another statute extension example is below.

\section{Irish Copyright and related Rights Act 2000}

Computer-generated work means "that the work is generated by computer in circumstances where the author of the work is not an individual".

Author means the person who creates a work and includes "(f) in the case of a work which is computer-generated, the person by whom the arrangements necessary for the creation of the work are undertaken".

This provision is perhaps arguably wider than the UK equivalent. It seems to suggest that there can be a work created but without an actual individual being present. However, it is unclear how proximate the person and their "arrangements" must be to the creation of the work. In the case of new and developing robots, etc., is the individual really making the arrangement? Consider a robot set down outside a jungle, which then makes its own way into the jungle, finds a location to rest, and waits to

\footnotetext{
30 An early reference includes A. Cruquenaire "Electronic Agents as Search Engines: Copyright Related Aspects (2001) 9(3) International Journal of Law and Information Technology p. 327.

31 P.M. Asaro "Remote-Control Crimes" (2011) 18(1) IEEE Robotics \& Automation Magazine p. 68.

32 ibid.
}


see if animals walk by it, and chooses some animals to photograph and not others, and how it photographs them, such as day filter, night filter, colour, black and white, thermal, etc. Various autonomous drones are sent off and will undertake automonous mapping and other activities. It cannot be said that a person whom may have build a device or part of a device is deciding or instructing that particular individual photographs or maps are to be taken, particularly if they cannot see the location, terrain, etc. Much will depend on what a court would interpret the work "arrangement" to mean in the circumstances of newer technology and previous contentious debates. Distinction might perhaps be drawn between a generated or taken photograph. Temporal issues, lack of individual human input, distance of human contact and direction, distance down-the-line, etc., will all be considered.

However, notwithstanding the above, it cannot be said that there is a guarantee of one or either of the above, or indeed other provisions, extending to robots, machine learning or AI in individual instances or in general in all instances. As is commented below, it could also be cautioned against from a policy perspective, shoe horning in new unforeseen scenarious to pre-existing provisions.

Sam Ricketson refers to the need for human authorship in the Australian context, particularly in light of the example of Telstra Corp Ltd $v$ Phone Directories Co Pty Ltd ${ }^{33}$.In the above case the Full Federal Court of Australia held that for original literary works, it is necessary to identify the specific works for which protection is claimed, and the human authors of those works. The works in the instant case were (white and yellow) page telephone directories. Copyright protection was denied on the basis that the compilation and production of the works was almost entirely automated. Any human contribution was either too anterior or too incidental or ministerial in nature (e.g. changes, corrections, etc.). Sam Ricketson comments that " $[\mathrm{t}] \mathrm{he}$ need for authors to be 'human' is a longstanding assumption in national copyright laws, particularly ... [following] the Berne Convention for the Protection of Literary and Artistic Works".

Previously the Australian Copyright Law Review Committee (the CLRC) examined issues of computer software. ${ }^{34}$ "This was in the context of works created with the use of computers, and was a matter that had been highlighted by the provision that had recently been adopted in the Copyright, Designs and Patents Act 1988 (UK) dealing with "computer generated works"" ${ }^{35}$ The CLRC distinguished between computer generated works and works created with the assistance of computers. "In the case of the latter, the CLRC saw no difficulty in applying protection on the same principles that extended to works created by using traditional means." ${ }^{\text {"36 }}$ The CLRC states that,

"In other words, if the materials produced with the assistance of a computer program amount to an original form of expression of an idea, and that expression comes within one of the recognized categories of works protected under the Copyright Act 1968 (the Act) the materials should also be protected as such, protection being granted regardless of how much easier the author's task is may have been made by the use of the computer program."37

Ricketson continues that,

"By contrast, the CLRC recognised that the difficulty arising with works generated solely or almost solely by computer processes would be that of identifying who was the human author of

33 S. Ricketson "The Need for Human Authorship - Australian Developments: Telstra Corp Ltd v Phone Directories Co Pty Ltd (Case Comment)" E.I.P.R. 2012, 34(1), 54. Telstra Corp Ltd v Phone Directories Co Pty Ltd (2011) 90 I.P.R. 1 (Fed Ct (Aus) (Full Ct)). Information and Publishing, Attorney-General's Department, 1995), Ch.13. Referred to ibid. S. Ricketson, above.

ibid.

CLRC, Computer Software Protection, 1995, para.13.07. Referred to ibid. 
the resultant expression. Several examples of this were given: satellite weather photographs and reports generated by an expert system. While these might have the final appearance of a protectable work, this did not avoid the need for inquiry into the statutory requirement that they must have authors, and human authors at that. In concluding this, the CLRC rejected the argument that this authorship requirement might be satisfied by focusing on the person who wrote the programs used for this purpose, or the person who may have entered the data in the knowledge base of the expert system from which the report was then generated by the expert system. This was not to deny that such productions might be worthy of some form of protection, but that this should not be under the rubric of original works of authorship:

'In so far as these types of computer-generated materials are deserving of protection it seems to the Committee that the protection that they should attract is more akin to that extended to neighbouring rights ... the protection extended to performers, producers of phonograms and broadcasting organizations." $" 38$

"This, then, was the solution that had been adopted in the UK legislation, but was not one that the CLRC recommended for Australia." ${ }^{, 39}$

The "Full Court's decision simply confirms the status quo: under the Copyright Act ... there must be identifiable human authors for copyright to subsist. On the detailed evidence before the trial judge, there was no basis for finding that such persons existed in the case of the directories in suit".

However, "[n]one of this is to deny that productions of this kind may, or should, be protectable as a matter of principle, whether pursuant to some tailor made sui generis regime contained in Pt IV of the Act or even some theory of unfair competition". "Ricketson cautions, however, "that this should not be shoehorned into Pt III [of the Act], which is concerned with authors and their works". ${ }^{42}$

\section{Related issues and concepts}

There are also various related concepts which might be considered in relation the issue of whether new works created by robots, machine learning and AI can be encompassed within the previous concept of computer generated works, and thus avail of copyright protection, and for whom. Some of these additional concepts are referred to below.

\section{Literate robots and non infringement}

J. Grimmelmann in referring to "Copyright for literate robots" refers as follows,

"Almost by accident, copyright law has concluded that it is for humans only: reading performed by computers doesn't count as infringement. Conceptually, this makes sense: Copyright's ideal of romantic readership involves humans writing for other humans. But in an age when more and more manipulation of copyrighted works is carried out by automated processes, this split between human reading (infringement) and robotic reading (exempt) ... Quietly, invisibly almost by accident, copyright has concluded that reading by robots doesn't count. Infringement is for humans only; when computers do it, it's fair use ... Copyright ignores robots. This ... is ... consistent with copyright's theory of the romantic reader." 43

While Grimmelmann is looking at the aspect of robotic reading and the machine or robotic reading not having been considered as an infringing act, this suffices to demonstrate that many aspects of

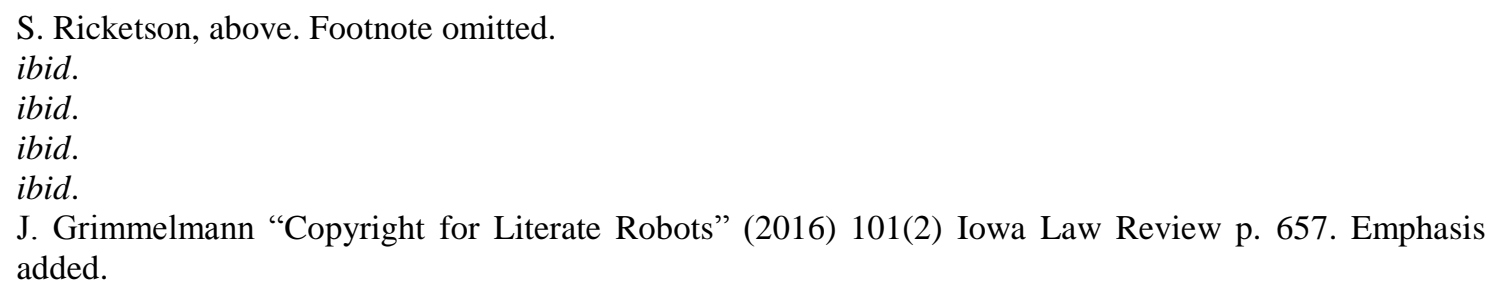


robots, machine learning and AI were not envisaged fully or at all when modern copyright statutes were enacted. This applies also to robot, machine learning and AI created or generated works. However, the new contemporary creations were also not envisaged even when the arm of copyright was extended to embrace the defined concept of (certain) computer generated works.

\section{Electronic and robot personhood}

J. Gunther et al refer to issues of robotics, privacy, electronic personhood in robotics, legal liability, admission, legal status, actions of software agents. "Law is not already prepared for the aspects coming with this new technology."

\section{Works of joint authorship}

Interesting and complicating issues may also involve the copyright concept of joint authorship of copyright works. For example, the UK Copyright, Designs and Patents Act 1988 refers to works of joint authorship in section 10. It provides that a work of joint authorship "means a work produced by the collaboration of two or more authors in which the contribution of each author is not distinct from that of the other author or authors." Section 22 of the Irish Copyright and Related Rights Act 2000 provides that "a work of joint authorship" means "a work produced by the collaboration of two or more authors in which the contribution of each author is not distinct from that of the other author or authors". The various potential areas of application of joint authorship, and or joint ownership, of copyright works in the context of robots, machine learning and AI may need to also be explored in detail.

\section{Infringement}

While the issue of protecting and enforcing rights by way of infringement action is an important aspect of the life cycle of copyright works, this aspect is beyond the current focus, which is confined the creation and existence of copyright in the above circumstances. ${ }^{46}$

\section{Conclusion}

While types of computer generated works will indeed be protected, in particular given the express and deliberate expansion of the copyright regime)(in certain jurisdictions at least), to protect these works. However, there is no assurance that absolutely every type of computer generated work will be encapsulated in the prior express protections. Currently there is an explosion in new forms of computer generated type works such as robots, machine learning, AI and the internet of things (IoT) more generally.

These were not originally envisaged and thus deserve a fuller contemporary analysis as this brief note discovers. The need for a wider analysis is supported by the vast efforts and resources being devoted to these new technology based activities. A wide jurisdictional and supra-national comparison may also be beneficial.

Commercial endeavours should be protected, however, in the instance of increasing and further downthe-line robotic and AI created works, it remains to be seen if and how copyright might currently

\footnotetext{
44 J. Gunther, F. Munch, S. Beck, S. Loffler, C. Leroux and R. Labruto, "Issues of Privacy and Electronic Personhood in Robotics" (2012) 2012 IEEE RO-MAN: The 21st IEEE International Symposium on Robot and Human Interactive Communication p. 815.

45 ibid.

46 There are also other developing issues and infringement issues to consider apart from the issue of computer generated works. "Spreading the News Online: A Fine Balance of Copyright and Freedom of Expression in News Aggregation” E.I.P.R. 2012, 34(11), 745. Note also comments of J. Grimmelmann, above.
} 
apply to assist in doing so, at least without further regulatory amendments. Assessments of new forms of computer generated works, and whether assessed on a case by case basis or grouped by category for the purposes of considering the applicability of copyright protection will need to be examined in more detail as these technologies and applications become increasingly commercialised.

Dr Paul Lambert adjunct lecturer, consultant (lambertp@tcd.ie) is the author of International Handbook of Social Media Laws; Gringras: The Laws of the Internet (fourth edition); A User's Guide to Data Protection (second edition); The Data Protection Officer: Profession, Rules and Role (2017); and various publications on intellectual property and data protection. 